\title{
Molecular analysis of thyroid tumors
}

\author{
Yuri E Nikiforov \\ Department of Pathology and Laboratory Medicine, University of Pittsburgh Medical Center, \\ Pittsburgh, PA, USA
}

\begin{abstract}
In the recent years, a large number of molecular alterations in thyroid cancer has been discovered and characterized. Some of these markers may have significant diagnostic utility, can be used for tumor prognostication, and serve as potential therapeutic targets. The diagnostic utility of these markers is of particular importance in thyroid fine-needle aspiration samples. Some molecular markers, such as BRAF, offer help in risk stratification and can be potentially used to optimize surgical and postsurgical management of patients with thyroid cancer. This review discusses major molecular alterations known to occur in thyroid cancer, focusing on those markers that have been extensively characterized, carry clinical significance, and are being introduced into pathology practice.

Modern Pathology (2011) 24, S34-S43; doi:10.1038/modpathol.2010.167
\end{abstract}

Keywords: BRAF; cancer; RET/PTC; RAS; thyroid

In the recent years, our understanding of molecular genetics of thyroid cancer has expanded dramatically. This knowledge contributes to better understanding of thyroid tumor biology and has started to translate into clinical practice as an ancillary tool for cytological and pathological diagnosis of thyroid cancer and for better tumor prognostication.

\section{Molecular alterations in thyroid cancer}

Four mutation types, that is, $B R A F$ and $R A S$ point mutations and RET/PTC and $P A X 8$ /peroxisome proliferator-activated receptor $\gamma(P P A R \gamma)$ rearrangements, constitute the majority of mutations known to occur in the two most common types of thyroid cancer, papillary and follicular carcinoma. At this time, they carry the highest impact on tumor diagnosis and prognostication. Papillary carcinomas harbor point mutations of the BRAF and RAS genes and RET/PTC rearrangements, all of which are able to activate the mitogen-activated protein kinase (MAPK) pathway. These mutually exclusive mutations are found in $>70 \%$ of papillary thyroid carcinomas. ${ }^{1-4}$ Follicular carcinomas are known to harbor either $R A S$ mutations or PAX8/PPAR $\gamma$ rearrangement. These mutations are also mutually

Correspondence: Dr YE Nikiforov, MD, PhD, Department of Pathology and Laboratory Medicine, University of Pittsburgh, UPMC Presbyterian, 200 Lothrop Street, Room C-606, Pittsburgh, PA 15213, USA.

E-mail: nikiforovye@upmc.edu

Received 15 July 2010; accepted 28 July 2010 exclusive and identified in $\sim 75 \%$ of follicular carcinomas. ${ }^{5}$

Another type of genetic alterations in thyroid cancer involve the PI3K/AKT signaling pathway, although they are rare in well-differentiated thyroid cancer and have higher prevalence in lessdifferentiated thyroid carcinomas. $^{6-8}$ Additional mutations known to occur in poorly differentiated and anaplastic carcinomas involve the TP53 and CTNNB1 genes. ${ }^{9}$ However, these mutations are rare in well-differentiated papillary or follicular carcinoma. TRK rearrangement represents another type of chromosomal rearrangement that occurs in papillary thyroid carcinomas, ${ }^{10-12}$ although its prevalence is low, particularly in North America $(<5 \%)$.

\section{BRAF}

Mutations of the BRAF gene have been reported in $35-70 \%$ of papillary thyroid carcinomas, although in most studies the prevalence in close to $40-45 \%$, making it the most common known genetic event in papillary thyroid carcinomas. ${ }^{2,13,14}$ The vast majority ( $>95 \%$ ) of BRAF mutations found in thyroid cancer are a thymine to adenine transversion at nucleotide 1799 (T1799A) leading to a substitution of valine by glutamic acid at residue 600 of the protein (V600E). This point mutation leads to constitutive activation of BRAF kinase and chronic stimulation of the MAPK pathway, and is tumorigenic for thyroid cells. Other and rare mechanisms of BRAF activation in thyroid papillary cancer include K601E point mutation, small in-frame insertions or deletions 

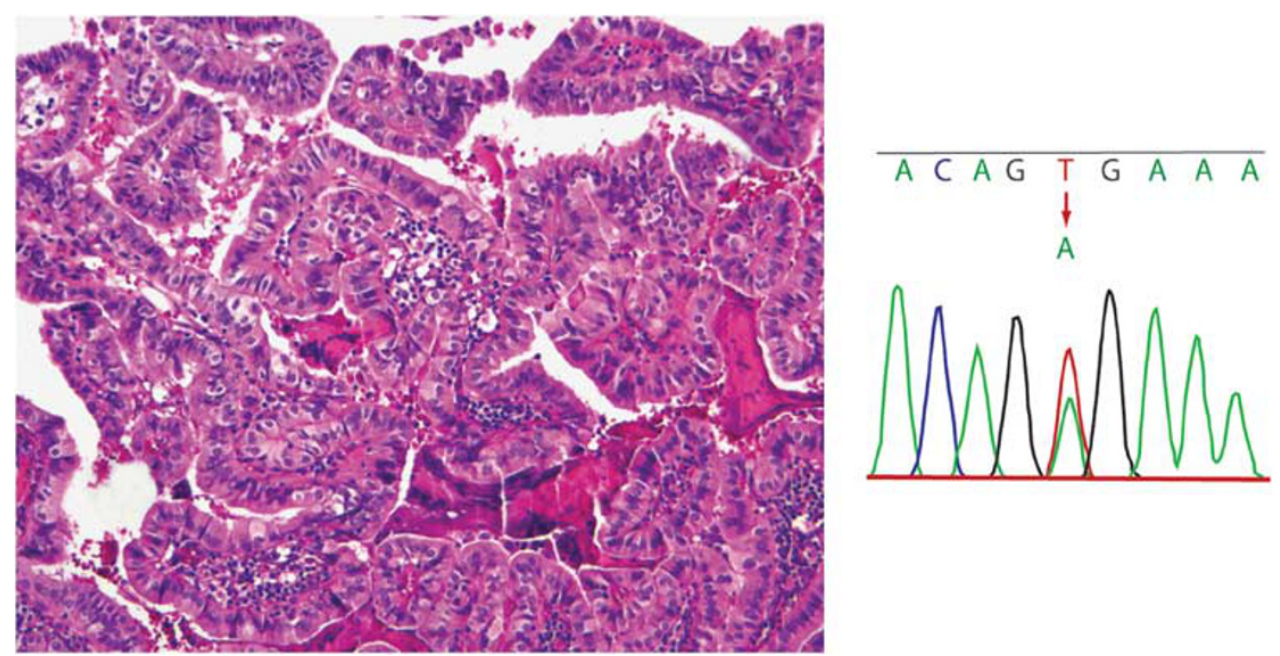

Figure 1 Left: Microscopic appearance of the tall cell variant papillary carcinoma. Right: The tumor was positive for BRAF codon 600 GTG $\rightarrow$ GAG mutation leading to V600E, as detected by Sanger sequencing.

surrounding codon $600,{ }^{15}$ and $A K A P 9 / B R A F$ rearrangement, which is more common in papillary carcinomas associated with radiation exposure. ${ }^{16}$

$B R A F$ V600E mutation has a strong association with specific histological variants of papillary carcinoma. It is highly prevalent in the tall cell variant of papillary carcinoma (Figure 1), where it occurs in $70-80 \%$ of cases, and in tumors with classic papillary growth $(\sim 60 \%) .^{1,13,17}$ Many BRAFpositive tumors are classic papillary carcinomas with focally prominent tall cell features or diffuse borderline tall cell features. BRAF-positive classic papillary carcinomas typically have an invasive border and may show focal areas composed of tumor cells with tall cell features. On the contrary, $B R A F$ V600E is found only in about $10 \%$ of follicular variants of papillary carcinoma. Another $B R A F$ point mutation, K601E, which is overall rare, is found mostly in the follicular variant of papillary carcinoma. ${ }^{18,19}$ BRAF V600E mutation can also be seen in anaplastic and poorly differentiated thyroid carcinomas arising from papillary carcinoma. ${ }^{17,20,21}$ However, BRAF V600E is not found in follicular carcinomas and benign thyroid nodules, and therefore among primary thyroid lesions it represents a specific marker of papillary carcinoma and related tumor types.

In addition to higher incidence in the tall cell variant of papillary carcinoma, BRAF V600E mutation has also been shown to correlate with other aggressive characteristics of papillary carcinomas, including extrathyroidal extension, advanced tumor stage at presentation, and lymph node or distant metastases. ${ }^{17,20,22,23}$

\section{RET/PTC}

$R E T / P T C$ rearrangement is another genetic alteration found in papillary carcinomas. ${ }^{24}$ It is formed by the fusion between the $3^{\prime}$ portion of the RET receptor tyrosine kinase gene and the $5^{\prime}$ portion of various unrelated genes. Two most common rearrangement types, RET/PTC1 and RET/PTC3, are intrachromosomal inversions as both $R E T$ and its respective fusion partner genes, $\mathrm{H} 4$ and NCOA4 (also known as ELE1), are located on chromosome $10 . .^{25-27}$ $R E T / P T C 2$ and nine more recently identified types of RET/PTC are all interchromosomal translocations (reviewed in Ciampi et $a{ }^{28}$ ). All rearrangement types contain the intact tyrosine kinase domain of the RET receptor and enables the RET/PTC chimeric protein to activate the RAS-RAF-MAPK cascade and initiate thyroid tumorigenesis.

$R E T / P T C$ rearrangements are found on average in $10-20 \%$ of adult sporadic papillary carcinomas, although its prevalence is highly variable between various observations, largely because of the difference in sensitivity of the detection methods and also because of some geographical variability. ${ }^{29,30}$ $R E T / P T C$ occur with higher incidence in patients with the history of radiation exposure (50-80\%) and in papillary carcinomas from children and young adults (40-70\%). ${ }^{31-34}$ The distribution of RET/PTC rearrangement within tumor cells can vary from involving most of neoplastic cells (clonal RET/PTC) to being detected only in a small fraction $(<1 \%)$ of tumor cells (nonclonal RET/PTC). ${ }^{35,36}$ Although $R E T / P T C$ has been found in several studies in adenomas and other benign thyroid lesions, it can be assumed that clonal RET/PTC (ie, rearrangement that is found in most cells within the tumor) is reasonably specific for papillary thyroid carcinoma. ${ }^{29,35}$ Two groups have reported the occurrence of $R E T / P T C$ in hyalinizing trabecular tumors. ${ }^{37-39}$ In one observation, four tumors showed RET expression by immunohistochemistry and three of those were found to harbor RET/PTC1 rearrangement by RT-PCR. ${ }^{37}$ In another study, RET/PTC1 was detected in six out of eight hyalinizing trabecular adenomas by RT-PCR. ${ }^{38}$ These findings provide 
evidence suggesting that hyalinizing trabecular tumors represent a peculiar variant of papillary carcinoma. However, these studies did not investigate whether or not RET/PTC was present in the majority of cells within these tumors and therefore cannot provide conclusive biological evidence for linkage between papillary carcinoma and hyalinizing trabecular tumor.

In papillary thyroid carcinomas, RET/PTC1 is the most common and comprises $60-70 \%$ of all rearrangement types, whereas RET/PTC3 accounts for $20-30 \%$ and $R E T / P T C 2$ and other novel rearrangement types for $<5 \%$. $^{11,40} R E T / P T C$-positive papillary carcinomas, particularly those carrying RET/PTC1 rearrangement, are typically present at younger age and have a high rate of lymph node metastases. ${ }^{1}$ Most RET/PTC-positive tumors, particularly those harboring RET/PTC1, show classic papillary growth pattern, and RET/PTC1 appears to be more common in papillary microcarcinomas. ${ }^{40-42}$ The follicular variant of papillary carcinoma shows low prevalence of RET/PTC. ${ }^{34,40}$ Among papillary carcinomas in children exposed to radiation after the Chernobyl accident, a strong correlation between different $R E T / P T C$ types and morphological variants of papillary carcinoma has been observed. In these populations, the solid variant of papillary carcinoma was associated with $R E T / P T C 3$ and classic papillary carcinoma with $R E T / P T C 1 .^{31,32,43}$ However, it remains unclear whether such phenotype-genotype correlation exists in the general population. It has not been found in a study of sporadic solid variant and classic papillary carcinomas, although the number of cases analyzed for RET/PTC in this study was small. ${ }^{44}$

\section{RAS}

Point mutations of the $R A S$ gene are not restricted to a particular type of thyroid tumors and found in follicular carcinomas, papillary carcinomas, and follicular adenomas. The three human RAS genes
(HRAS, KRAS, and NRAS) encode highly related G-proteins that propagate signals arising from cell membrane receptors to various intracellular targets. Point mutations in the specific domains of the $R A S$ gene either increase its affinity for GTP (mutations in codons 12 and 13) or inactivate its autocatalytic GTPase function (mutation in codon 61), resulting in permanent RAS activation and chronic stimulation of its downstream targets along the MAPK and PI3K/AKT signaling pathways.

In thyroid tumors, mutations involving NRAS codon 61 and HRAS codon 61 are by far the most common, although mutations have been found in different hotspots of all three genes. In papillary carcinomas, RAS mutations occur in $15-20 \%$ of tumors. ${ }^{45-50}$ Papillary carcinomas harboring RAS mutation almost always have the follicular variant histology (Figure 2); this mutation also correlates with significantly less prominent nuclear features of papillary carcinoma, more frequent encapsulation, and low rate of lymph node metastases. ${ }^{1,51} R A S$ mutations are also found in $40-50 \%$ of conventional type follicular carcinomas ${ }^{48,52-56}$ and $20-40 \%$ of conventional type follicular adenomas. ${ }^{45,52-55} \mathrm{In}$ adenomas, the mutations appeared to be more common in tumors with a microfollicular growth pattern. ${ }^{52}$ A lower incidence has been reported in oncocytic tumors, in which only $0-4 \%$ of adenomas and $15-25 \%$ of carcinomas appeared to be affected. ${ }^{54,57,58}$ RAS mutations have also been detected in few cold adenomatous nodules and goiter nodules, ${ }^{45,54,59}$ although it is likely that these lesions are true neoplasms and therefore should be designated as follicular adenomas, despite their frequent macrofollicular colloid-rich histology.

\section{PAX8/PPAR}

$P A X 8 / P P A R \gamma$ rearrangement is a result of translocation between chromosomes 2 and $3, \mathrm{t}(2 ; 3)(\mathrm{q} 13 ; \mathrm{p} 25)$, leading to the fusion between the $P A X 8$ gene coding
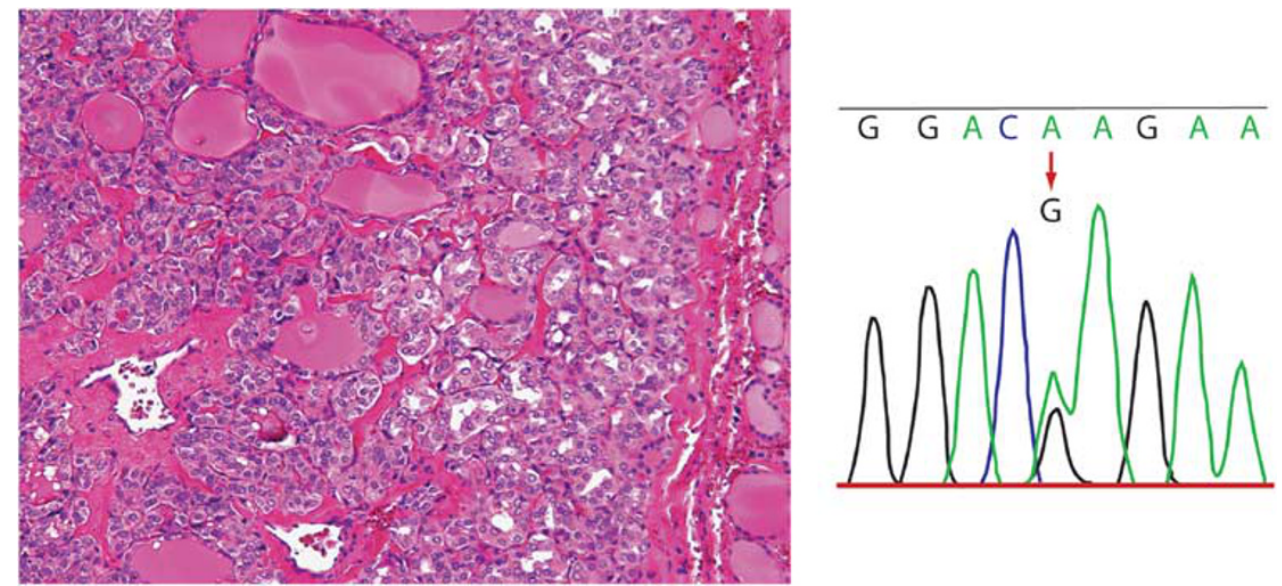

Figure 2 Left: Microscopic appearance of the encapsulated follicular variant of papillary carcinoma. Right: The tumor was positive for NRAS codon 61 CAA $\rightarrow$ CGA mutation leading to Q61R, as detected by Sanger sequencing. 
for the thyroid-specific paired domain transcription factor, and the PPAR $\gamma$ gene. ${ }^{60} P A X 8 / P P A R \gamma$ rearrangement leads to strong overexpression of the PPAR $\gamma$ protein, although the mechanisms of cell transformation induced by this genetic event are yet to be fully understood.

$P A X 8 / P P A R \gamma$ is found in $30-40 \%$ of conventional type follicular carcinomas, and with lower prevalence in oncocytic carcinomas. ${ }^{5,61,62}$ Tumors harboring $P A X 8 / P P A R \gamma$ tend to present at a younger age, are smaller in size, have a solid/nested growth pattern, and more frequently reveal vascular inva-

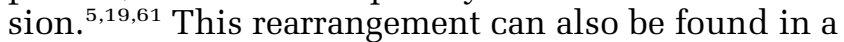
small fraction (2-10\%) of follicular adenomas and in some $(<5 \%)$ follicular variant papillary carcinomas. ${ }^{5,19,62,63}$ Follicular adenomas positive for $P A X 8 /$ $P P A R \gamma$ typically have a thick capsule and show the immunohistochemical profile characteristic of thyroid cancer, suggesting that they may represent preinvasive (in situ) follicular carcinomas or malignant tumors in which invasion was overlooked during histological examination. ${ }^{5}$ Single studies have reported a significantly higher frequency of $P A X 8 / P P A R \gamma$ rearrangement in follicular adenomas and follicular variant papillary carcinomas. ${ }^{19}$ Another type of the PPAR gene fusion, CREB3L2/ $P P A R \gamma$, has been reported in 1 out of 42 follicular carcinomas. ${ }^{64}$

\section{Sample requirements and techniques for molecular analysis}

Modern molecular techniques allow the detection of various genetic alterations in fine-needle aspiration (FNA) samples and in various types of surgically removed tumor tissues. A snap-frozen tumor sample generally represents the best source of material for molecular testing. If the fixed material has to be used, the formalin fixation or cytological ethanol fixation should be used. Tissue exposed to decalcifying solution, B5, and most of other special fixatives degrade nucleic acids and therefore cannot be used for molecular analysis. The choice of most appropriate detection technique is determined by the mutation type and samples type available for the analysis.

Testing for point mutations, such as those of $B R A F$ and $R A S$, is relatively straightforward and can be reliably performed in freshly frozen and fixed samples. A variety of available molecular techniques can be used, including conventional PCR and Sanger sequencing, pyrosequencing, real-time PCR amplification and post-PCR melting curve analysis, allele-specific PCR, and others. ${ }^{2,17,65-70}$ These techniques typically provide a reliable and sensitive detection of $B R A F$ mutations in various types of thyroid samples. One study that compared four different approaches, that is, probe-specific real-time PCR, real-time allele-specific PCR, direct sequencing, and colorimetric assay, found all the techniques showing similarly high sensitivity in the detection of $B R A F$ mutation in fixed FNA samples. ${ }^{66}$
The choice of a method for the detection of chromosomal rearrangements, such as RET/PTC and $P A X 8 / P P A R \gamma$, is dictated largely by the type of sample available. When freshly collected or snapfrozen FNA or tumor tissue samples are available, the testing can be reliably performed by RT-PCR. The sensitivity of detection should generally be not higher than $1 \%$ of tumor cells (ie, should detect $1 \%$ or more tumors cells in the background of normal cells) to avoid detecting nonclonal rearrangements, which have no diagnostic implications. When only formalin-fixed and paraffin-embedded tissue is available for testing, fluorescence in situ hybridization is the assay of choice. The appropriate cutoff levels have to be established, which generally should be no $<8-12 \%$ of cells with the rearrangement pattern of signals, as this assure the reliable detection and avoid detecting nonclonal rearrangements. ${ }^{71}$ Usage of RT-PCR for clinical detection of RET/PTC and PAX8/PPAR $\gamma$ rearrangements in formalin-fixed and paraffin-embedded tissues should be avoided due to severe RNA degradation, which can not be compensated by choosing ultrasensitive conditions. The latter results in the loss of diagnostic specificity of the test due to increased detection of nonclonal rearrangement and higher risk of false-positive results.

\section{Role of molecular markers in thyroid cancer diagnosis}

\section{Molecular Analysis of FNA Samples}

FNA cytology is currently the most reliable diagnostic test for thyroid nodules and establishes the definitive diagnosis of a benign or malignant lesion in the majority of cases, whereas $10-40 \%$ of all FNA samples are diagnosed as indeterminate for malignancy. ${ }^{72-75}$ The general category of indeterminate cytology encompasses several subcategories, that is, follicular lesion of indeterminate significance (FLUS), follicular neoplasm/Hürthle cell neoplasm, and suspicious for malignancy, which correlate with the estimated risk of malignancy of $5-10,20-30$, and $50-75 \%$, respectively. ${ }^{76}$ Owing to the lack of definitive diagnosis, most patients with indeterminate cytology undergo surgery, although only $8-17 \%$ of surgically removed thyroid nodules are malignant. ${ }^{77,78}$ Patients with indeterminate FNA cytology and malignant tumors are not adequately treated as well, as most of them initially undergo thyroid lobectomy and later have another surgery to complete thyroidectomy.

Molecular testing of FNA samples may significantly improve the accuracy of cytological diagnosis of thyroid nodules. Most experience to date is accumulated for $B R A F$ mutations. The results of $B R A F$ testing in 2766 FNA samples have been reported in 18 prospective and retrospective studies. ${ }^{65,66,69,70,79-92}$ Among 581 BRAF-positive nodules tested in FNA samples in these studies, 
580 were papillary carcinomas on pathological examination of the resected nodules, whereas one was diagnosed as a benign nodule, ${ }^{92}$ resulting in the false-positive rate of $0.2 \%$. This reportedly benign nodule had a histopathological diagnosis of 'atypical nodular hyperplasia' and was not examined using modern immunohistochemical techniques that are helpful in the diagnosis of thyroid malignancy in difficult cases. ${ }^{93}$ Importantly, $15-40 \%$ of $B R A F$-positive FNA samples are indeterminate or nondiagnostic by cytology, ${ }^{69,70,82,85,87,88}$ indicating that testing for $B R A F$ is helpful in establishing the definitive diagnosis of cancer in nodules with indeterminate cytology.

In addition to $B R A F$, several studies have explored the possibility of the detection of RET/PTC, TRK, or $R A S$ mutations in thyroid FNA samples. ${ }^{88,94,95}$ However, the biggest diagnostic impact can be achieved by testing FNA samples for a panel of mutations rather then for a single mutation. Recent studies have explored the diagnostic utility of molecular testing for a panel of mutations consisting of BRAF, RAS, RET/PTC, and PAX8/PPAR $\gamma^{69,96}$ One study examined 470 consecutive FNA samples from thyroid nodules that were prospectively tested and yielded 32 mutations. ${ }^{69}$ The presence of any mutation was a strong predictor of cancer, as $31(97 \%)$ of mutation-positive nodules had a malignant diagnosis after surgery and one case $(3 \%)$ was a follicular adenoma. This study showed that testing for a panel of mutations was particularly useful in nodules with indeterminate cytology, especially in the lowest risk subgroup of indeterminate cytology, that is, FLUS. In this subgroup, the positive mutational status had a $100 \%$ accuracy in predicting the risk of a malignancy, whereas mutation-negative nodules were all benign. In addition, this study showed that molecular testing decreased the false-negative rate of cytology from 2.1 to $0.9 \%{ }^{69}$ Another study focused only on the FLUS group of cytology samples and found that testing for mutations had a $100 \%$ positive predictive value and $92 \%$ negative predictive value for cancer in this group (Figure 3) ${ }^{96}$ Regarding specific mutations that constituted the panel, BRAF, RET/PTC, and PAX8/PPAR $\gamma$ mutations had a $100 \%$ positive predictive value for cancer in both studies. ${ }^{69,96}$ Detection of RAS mutation, which was the second most common mutation after $B R A F$, also appeared to be of high diagnostic value in FNA samples, as it conferred an $87-100 \%$ probability of malignancy. Importantly, RAS mutations were identified in tumors, which are difficult to diagnose by cytology alone, that is, follicular variant of papillary carcinoma and follicular carcinoma. The accumulation of knowledge on diagnostic use of molecular markers has been reflected in the Revised Management Guidelines for Patients with Thyroid Nodules and Differentiated Thyroid Cancer, recently released by the American Thyroid Association. ${ }^{97}$ The guidelines recommend the use of molecular markers, such as BRAF, RAS, RET/PTC, and PAX8/PPAR $\gamma$, for

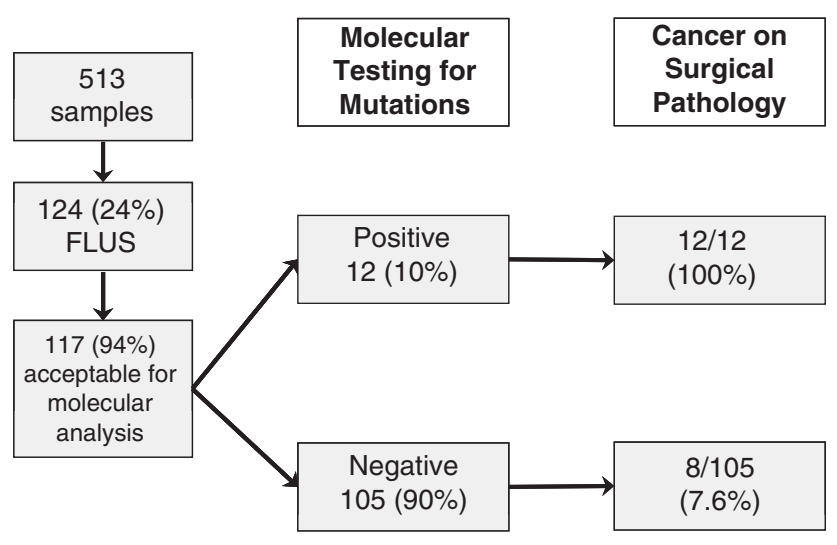

Figure 3 Diagnostic significance of mutational testing in thyroid FNA samples with FLUS cytology. On the basis of the results reported by Ohori et al. ${ }^{96}$

indeterminate FNA cytology to help guide patient management.

\section{Molecular Analysis of Surgically Removed Tumors}

Molecular testing of surgically removed thyroid samples has a rather limited diagnostic impact in papillary carcinomas. When the histopathological diagnosis of papillary carcinoma is suspected, testing of tumor tissue for BRAF and clonal RET/ $P T C$ can be of diagnostic value as their presence is a strong indicator of papillary carcinoma. However, many tumors carrying these mutations are classic papillary carcinomas or tall cell variants, and in those cases the histological diagnosis is typically straightforward. The follicular variant of papillary carcinoma, which more often imposes diagnostic difficulty on surgical pathology examination, most frequently has RAS mutations. However, RAS mutation cannot be used to define malignancy as it can be found in follicular adenomas.

In follicular carcinomas, testing for PAX8/PPAR $\gamma$ rearrangement may be of significant diagnostic value. This mutation is characteristically seen in follicular carcinomas, although, as discussed earlier, it can also be seen in a small fraction of follicular adenomas. The finding of $P A X 8 / P P A R \gamma$ should prompt the pathologist to perform an exhaustive search for vascular or capsular invasion. The invasion may not be seen at first, but is detected in many PAX8/PPAR $\gamma$-positive follicular tumors after examination of the entire tumor capsule in multiple histological levels. ${ }^{5,61,98}$

\section{Molecular markers of aggressiveness in thyroid cancer}

\section{BRAF}

$B R A F$ V600E mutation is generally considered as a reliable prognostic marker for papillary carcinoma. 
Its association with more unfavorable tumor behavior has been documented in most studies involving sufficiently large cohorts of patients, although some observations have not found such an association (reviewed in $\mathrm{Xing}^{23}$ ). In many studies, BRAF V600E mutation correlate with aggressive tumor characteristics, such as tall cell variant, extrathyroidal extension, advanced tumor stage at presentation, and lymph node or distant metastases (reviewed in Xing ${ }^{23}$ ). More importantly, BRAF V600E has been found to be an independent predictor of treatment failure and tumor recurrence, even in patients with low-stage disease. ${ }^{22,99,100} \mathrm{~A}$ recent study of 102 papillary carcinomas with median follow-up of 15 years demonstrated that BRAF V600E mutation was an independent risk factor for tumor-related death. ${ }^{101}$ BRAF V600E association with disease-free probability remains significant when mutation was detected not only in surgically removed tumor samples but also in thyroid FNA samples. ${ }^{90}$

BRAF activation via BRAF V600E mutation in thyroid cells appears to lead to the alteration of function of sodium iodide symporter (NIS) and other genes metabolizing iodide, which is likely to be responsible for the decreased ability of tumors with $B R A F$ mutation to trap radioiodine and treatment failure of the recurrent disease. ${ }^{8,102,103} B R A F$ mutation also predisposes to tumor dedifferentiation and progression to poorly differentiated and anaplastic carcinoma, which is likely to contribute to less favorable prognosis for these patients.

The prognostic implications of BRAF mutation could be of particular importance in papillary microcarcinomas, which are incidentally discovered tumors of $\leq 1 \mathrm{~cm}$ in size. These tumors are commonly found in thyroid samples removed for larger benign nodules. Most of the microcarcinomas are indolent tumors cured by surgical resection, although some of them demonstrate metastatic behavior, recur and may lead to patient death, and those require more aggressive treatment. ${ }^{104}$ The role of BRAF mutation in defining a subset of aggressive papillary microcarcinomas remains to be fully defined. However, several recent studies have demonstrated that BRAF mutation in thyroid microcarcinomas correlates with either high rate of extrathyroidal tumor extension or lymph node metastasis or both of these features. ${ }^{105-107}$

\section{RAS}

The role of RAS mutation in predicting more aggressive tumor behavior is not well defined. As this mutation is also found in benign follicular adenomas, the RAS status by itself cannot be used for tumor prognostication. Some evidence exists, however, that RAS mutations in invasive follicular and papillary carcinoma may correlate with more unfavorable prognosis, although this correlation is far from being conclusively established.
Several studies have found a significant correlation between RAS mutation and metastatic behavior of follicular carcinomas, especially with respect to bone metastases, which may be due to the role of $R A S$ mutation in promoting tumor dedifferentiation and transformation to anaplastic carcinoma. ${ }^{46,48,108,109}$ The association between mutant $R A S$ and more aggressive behavior of papillary carcinoma has been reported in a series of 91 tumors followed up on average for 14 years, in which $R A S$ mutation was found to correlate with distant metastasis and significantly higher mortality rate. ${ }^{47}$ On the other hand, RAS mutations are frequently found in encapsulated follicular variant of papillary carcinoma, the tumor with an indolent behavior. ${ }^{51,110}$ Therefore, it is likely that RAS mutations mark a subset of widely invasive well-differentiated thyroid carcinomas, which are prone to metastatic spread and dedifferentiation and therefore entail higher mortality, but this mutation can not be used as a universal prognostic marker for all types of thyroid cancer.

\section{Disclosure/conflict of interest}

The author declares no conflict of interest.

\section{References}

1 Adeniran AJ, Zhu Z, Gandhi M, et al. Correlation between genetic alterations and microscopic features, clinical manifestations, and prognostic characteristics of thyroid papillary carcinomas. Am J Surg Pathol 2006;30:216-222.

2 Kimura ET, Nikiforova MN, Zhu Z, et al. High prevalence of BRAF mutations in thyroid cancer: genetic evidence for constitutive activation of the RET/PTC-RAS-BRAF signaling pathway in papillary thyroid carcinoma. Cancer Res 2003;63:1454-1457.

3 Soares P, Trovisco V, Rocha AS, et al. BRAF mutations and RET/PTC rearrangements are alternative events in the etiopathogenesis of PTC. Oncogene 2003;22:4578-4580.

4 Frattini M, Ferrario C, Bressan P, et al. Alternative mutations of BRAF, RET and NTRK1 are associated with similar but distinct gene expression patterns in papillary thyroid cancer. Oncogene 2004;23: 7436-7440.

5 Nikiforova MN, Lynch RA, Biddinger PW, et al. RAS point mutations and PAX8-PPAR gamma rearrangement in thyroid tumors: evidence for distinct molecular pathways in thyroid follicular carcinoma. J Clin Endocrinol Metab 2003;88:2318-2326.

6 Garcia-Rostan G, Costa AM, Pereira-Castro I, et al. Mutation of the PIK3CA gene in anaplastic thyroid cancer. Cancer Res 2005;65:10199-10207.

7 Hou P, Liu D, Shan Y, et al. Genetic alterations and their relationship in the phosphatidylinositol 3-kinase/Akt pathway in thyroid cancer. Clin Cancer Res 2007;13:1161-1170.

8 Ricarte-Filho JC, Ryder M, Chitale DA, et al. Mutational profile of advanced primary and metastatic 
radioactive iodine-refractory thyroid cancers reveals distinct pathogenetic roles for BRAF, PIK3CA, and AKT1. Cancer Res 2009;69:4885-4893.

9 Kondo T, Ezzat S, Asa SL. Pathogenetic mechanisms in thyroid follicular-cell neoplasia. Nature Rev 2006; 6:292-306

10 Pierotti MA, Bongarzone I, Borello MG, et al. Cytogenetics and molecular genetics of carcinomas arising from thyroid epithelial follicular cells. Genes Chromosomes Cancer 1996;16:1-14.

11 Bongarzone I, Vigneri P, Mariani L, et al. RET/NTRK1 rearrangements in thyroid gland tumors of the papillary carcinoma family: correlation with clinicopathological features. Clin Cancer Res 1998;4:223228.

12 Musholt TJ, Musholt PB, Khaladj N, et al. Prognostic significance of RET and NTRK1 rearrangements in sporadic papillary thyroid carcinoma. Surgery 2000;128:984-993.

13 Xing M. BRAF mutation in thyroid cancer. Endocr Relat Cancer 2005;12:245-262.

14 Cohen Y, Xing M, Mambo E, et al. BRAF mutation in papillary thyroid carcinoma. J Natl Cancer Inst 2003;95:625-627.

15 Chiosea S, Nikiforova $\mathrm{M}$, Zuo $\mathrm{H}$, et al. A novel complex BRAF mutation detected in a solid variant of papillary thyroid carcinoma. Endocr Pathol 2009;20:122-126.

16 Ciampi R, Knauf JA, Kerler R, et al. Oncogenic AKAP9-BRAF fusion is a novel mechanism of MAPK pathway activation in thyroid cancer. J Clin Invest 2005;115:94-101.

17 Nikiforova MN, Kimura ET, Gandhi M, et al. BRAF mutations in thyroid tumors are restricted to papillary carcinomas and anaplastic or poorly differentiated carcinomas arising from papillary carcinomas. J Clin Endocrinol Metab 2003;88:5399-5404.

18 Trovisco V, Soares P, Preto A, et al. Type and prevalence of BRAF mutations are closely associated with papillary thyroid carcinoma histotype and patients' age but not with tumour aggressiveness. Virchows Arch 2005;446:589-595.

19 Castro P, Rebocho AP, Soares RJ, et al. PAX8PPARgamma rearrangement is frequently detected in the follicular variant of papillary thyroid carcinoma. J Clin Endocrinol Metab 2006;91:213-220.

20 Namba H, Nakashima M, Hayashi T, et al. Clinical implication of hot spot BRAF mutation, V599E, in papillary thyroid cancers. J Clin Endocrinol Metab 2003;88:4393-4397.

21 Begum S, Rosenbaum E, Henrique R, et al. BRAF mutations in anaplastic thyroid carcinoma: implications for tumor origin, diagnosis and treatment. Mod Pathol 2004;17:1359-1363.

22 Xing M, Westra WH, Tufano RP, et al. BRAF mutation predicts a poorer clinical prognosis for papillary thyroid cancer. J Clin Endocrinol Metab 2005;90:6373-6379.

23 Xing M. BRAF mutation in papillary thyroid cancer: pathogenic role, molecular bases, and clinical implications. Endocr Rev 2007;28:742-762.

24 Santoro M, Carlomagno F, Hay ID, et al. Ret oncogene activation in human thyroid neoplasms is restricted to the papillary cancer subtype. J Clin Invest 1992;89:1517-1522.

25 Grieco M, Santoro M, Berlingieri MT, et al. PTC is a novel rearranged form of the ret proto-oncogene and is frequently detected in vivo in human thyroid papillary carcinomas. Cell 1990;60:557-563.

26 Santoro M, Dathan NA, Berlingieri MT, et al. Molecular characterization of RET/PTC3; a novel rearranged version of the RETproto-oncogene in a human thyroid papillary carcinoma. Oncogene 1994;9:509-516.

27 Bongarzone I, Butti MG, Coronelli S, et al. Frequent activation of ret protooncogene by fusion with a new activating gene in papillary thyroid carcinomas. Cancer Res 1994;54:2979-2985.

28 Ciampi R, Giordano TJ, Wikenheiser-Brokamp K, et al. HOOK3-RET: a novel type of RET/PTC rearrangement in papillary thyroid carcinoma. Endocr Relat Cancer 2007;14:445-452.

29 Nikiforov YE. RET/PTC rearrangement in thyroid tumors. Endocr Pathol 2002;13:3-16.

30 Tallini G, Asa SL. RET oncogene activation in papillary thyroid carcinoma. Adv Anat Pathol 2001; 8:345-354.

31 Nikiforov YE, Rowland JM, Bove KE, et al. Distinct pattern of ret oncogene rearrangements in morphological variants of radiation-induced and sporadic thyroid papillary carcinomas in children. Cancer Res 1997;57:1690-1694.

32 Rabes HM, Demidchik EP, Sidorow JD, et al. Pattern of radiation-induced RET and NTRK1 rearrangements in 191 post-chernobyl papillary thyroid carcinomas: biological, phenotypic, and clinical implications. Clin Cancer Res 2000;6:1093-1103.

33 Fenton CL, Lukes Y, Nicholson D, et al. The ret/PTC mutations are common in sporadic papillary thyroid carcinoma of children and young adults. J Clin Endocrinol Metab 2000;85:1170-1175.

34 Soares P, Fonseca E, Wynford-Thomas D, et al. Sporadic ret-rearranged papillary carcinoma of the thyroid: a subset of slow growing, less aggressive thyroid neoplasms? J Pathol 1998;185:71-78.

35 Zhu Z, Ciampi R, Nikiforova MN, et al. Prevalence of Ret/Ptc rearrangements in thyroid papillary carcinomas: effects of the detection methods and genetic heterogeneity. J Clin Endocrinol Metab 2006;91:2672-2677.

36 Unger $\mathrm{K}$, Zitzelsberger $\mathrm{H}$, Salvatore $\mathrm{G}$, et al. Heterogeneity in the distribution of RET/PTC rearrangements within individual post-Chernobyl papillary thyroid carcinomas. J Clin Endocrinol Metab 2004;89:4272-4279.

37 Papotti M, Volante M, Giuliano A, et al. RET/PTC activation in hyalinizing trabecular tumors of the thyroid. Am J Surg Pathol 2000;24:1615-1621.

38 Cheung CC, Boerner SL, MacMillan CM, et al. Hyalinizing trabecular tumor of the thyroid: a variant of papillary carcinoma proved by molecular genetics. Am J Surg Pathol 2000;24:1622-1626.

39 Salvatore G, Chiappetta G, Nikiforov YE, et al. Molecular profile of hyalinizing trabecular tumours of the thyroid: high prevalence of RET/PTC rearrangements and absence of B-raf and N-ras point mutations. Eur J Cancer 2005;41:816-821.

40 Tallini G, Santoro M, Helie $M$, et al. RET/PTC oncogene activation defines a subset of papillary thyroid carcinomas lacking evidence of progression to poorly differentiated or undifferentiated tumor phenotypes. Clin Cancer Res 1998;4:287-294.

41 Viglietto G, Chiappetta G, Martinez-Tello FJ, et al. RET/ PTC oncogene activation is an early event in thyroid carcinogenesis. Oncogene 1995;11:1207-1210. 
42 Sugg SL, Ezzat S, Rosen IB, et al. Distinct multiple RET/PTC gene rearrangements in multifocal papillary thyroid neoplasia. J Clin Endocrinol Metab 1998;83:4116-4122.

43 Thomas GA, Bunnell H, Cook HA, et al. High prevalence of RET/PTC rearrangements in Ukrainian and Belarussian post-Chernobyl thyroid papillary carcinomas: a strong correlation between RET/PTC3 and the solid-follicular variant. J Clin Endocrinol Metab 1999;84:4232-4238.

44 Nikiforov YE, Erickson LA, Nikiforova MN, et al. Solid variant of papillary thyroid carcinoma: incidence, clinical-pathologic characteristics, molecular analysis, and biologic behavior. Am J Surg Pathol 2001;25:1478-1484.

45 Namba H, Rubin SA, Fagin JA. Point mutations of ras oncogenes are an early event in thyroid tumorigenesis. Mol Endocrinol 1990;4:1474-1479.

46 Karga H, Lee JK, Vickery Jr AL, et al. Ras oncogene mutations in benign and malignant thyroid neoplasms. J Clin Endocrinol Metab 1991;73: 832-836.

47 Hara H, Fulton N, Yashiro T, et al. N-ras mutation: an independent prognostic factor for aggressiveness of papillary thyroid carcinoma. Surgery 1994;116: 1010-1016.

48 Basolo F, Pisaturo F, Pollina LE, et al. N-ras mutation in poorly differentiated thyroid carcinomas: correlation with bone metastases and inverse correlation to thyroglobulin expression. Thyroid 2000;10:19-23.

49 Ezzat S, Zheng L, Kolenda J, et al. Prevalence of activating ras mutations in morphologically characterized thyroid nodules. Thyroid 1996;6: 409-416.

50 Vasko VV, Gaudart J, Allasia C, et al. Thyroid follicular adenomas may display features of follicular carcinoma and follicular variant of papillary carcinoma. Eur J Endocrinol 2004;151:779-786.

51 Zhu Z, Gandhi M, Nikiforova MN, et al. Molecular profile and clinical-pathologic features of the follicular variant of papillary thyroid carcinoma. An unusually high prevalence of ras mutations. Am J Clin Pathol 2003;120:71-77.

52 Lemoine NR, Mayall ES, Wyllie FS, et al. High frequency of ras oncogene activation in all stages of human thyroid tumorigenesis. Oncogene 1989;4:159-164.

53 Suarez HG, du Villard JA, Severino M, et al. Presence of mutations in all three ras genes in human thyroid tumors. Oncogene 1990;5:565-570.

54 Esapa CT, Johnson SJ, Kendall-Taylor P, et al. Prevalence of Ras mutations in thyroid neoplasia. Clin Endocrinol (Oxf) 1999;50:529-535.

55 Motoi N, Sakamoto A, Yamochi T, et al. Role of ras mutation in the progression of thyroid carcinoma of follicular epithelial origin. Pathol Res Pract 2000;196:1-7.

56 Lemoine NR, Mayall ES, Wyllie FS, et al. Activated ras oncogenes in human thyroid cancers. Cancer Res 1988;48:4459-4463.

57 Schark C, Fulton N, Jacoby RF, et al. N-ras 61 oncogene mutations in Hurthle cell tumors. Surgery 1990;108:994-999; discussion 9-1000.

58 Tallini G, Hsueh A, Liu S, et al. Frequent chromosomal DNA unbalance in thyroid oncocytic (Hurthle cell) neoplasms detected by comparative genomic hybridization. Lab Invest 1999;79:547-555.
59 Krohn K, Reske A, Ackermann F, et al. Ras mutations are rare in solitary cold and toxic thyroid nodules. Clin Endocrinol (Oxf) 2001;55:241-248.

60 Kroll TG, Sarraf P, Pecciarini L, et al. PAX8-PPARgamma1 fusion oncogene in human thyroid carcinoma [corrected]. Science 2000;289:1357-1360.

61 French CA, Alexander EK, Cibas ES, et al. Genetic and biological subgroups of low-stage follicular thyroid cancer. Am J Pathol 2003;162:1053-1060.

62 Dwight T, Thoppe SR, Foukakis T, et al. Involvement of the PAX8/peroxisome proliferator-activated receptor gamma rearrangement in follicular thyroid tumors. J Clin Endocrinol Metabol 2003;88: 4440-4445.

63 Marques AR, Espadinha C, Catarino AL, et al. Expression of PAX8-PPAR gamma 1 rearrangements in both follicular thyroid carcinomas and adenomas. J Clin Endocrinol Metabol 2002;87:3947-3952.

64 Lui WO, Zeng L, Rehrmann V, et al. CREB3L2PPARgamma fusion mutation identifies a thyroid signaling pathway regulated by intramembrane proteolysis. Cancer Res 2008;68:7156-7164.

65 Hayashida N, Namba H, Kumagai A, et al. A rapid and simple detection method for the BRAF(T1796A) mutation in fine-needle aspirated thyroid carcinoma cells. Thyroid 2004;14:910-915.

66 Jin L, Sebo TJ, Nakamura N, et al. BRAF mutation analysis in fine needle aspiration (FNA) cytology of the thyroid. Diagn Mol Pathol 2006;15:136-143.

67 Rowe LR, Bentz BG, Bentz JS. Detection of BRAF V600E activating mutation in papillary thyroid carcinoma using PCR with allele-specific fluorescent probe melting curve analysis. J Clin Pathol 2007;60:1211-1215.

68 Sapio MR, Posca D, Troncone G, et al. Detection of BRAF mutation in thyroid papillary carcinomas by mutant allele-specific PCR amplification (MASA). Eur J Endocrinol 2006;154:341-348.

69 Nikiforov YE, Steward DL, Robinson-Smith TM, et al. Molecular testing for mutations in improving the fineneedle aspiration diagnosis of thyroid nodules. J Clin Endocrinol Metabol 2009;94:2092-2098.

$70 \mathrm{Kim}$ SK, Kim DL, Han HS, et al. Pyrosequencing analysis for detection of a BRAFV600E mutation in an FNAB specimen of thyroid nodules. Diagn Mol Pathol 2008;17:118-125

71 Zhu Z, Ciampi R, Nikiforova MN, et al. Prevalence of RET/PTC rearrangements in thyroid papillary carcinomas: effects of the detection methods and genetic heterogeneity. J Clin Endocrinol Metabol 2006;91: 3603-3610.

72 Cooper DS, Doherty GM, Haugen BR, et al. Management guidelines for patients with thyroid nodules and differentiated thyroid cancer. Thyroid 2006;16: 109-142.

73 Gharib H. Changing trends in thyroid practice: understanding nodular thyroid disease. Endocr Pract 2004;10:31-39.

74 Greaves TS, Olvera M, Florentine BD, et al. Follicular lesions of thyroid: a 5-year fine-needle aspiration experience. Cancer 2000;90:335-341.

75 Sclabas GM, Staerkel GA, Shapiro SE, et al. Fine-needle aspiration of the thyroid and correlation with histopathology in a contemporary series of 240 patients. Am J Surg 2003;186:702-709; discussion 9-10.

76 Baloch ZW, LiVolsi VA, Asa SL, et al. Diagnostic terminology and morphologic criteria for cytologic 
diagnosis of thyroid lesions: a synopsis of the National Cancer Institute Thyroid Fine-Needle Aspiration State of the Science Conference. Diagn Cytopathol 2008;36:425-437.

77 Baloch ZW, Fleisher S, LiVolsi VA, et al. Diagnosis of 'follicular neoplasm': a gray zone in thyroid fineneedle aspiration cytology. Diagn Cytopathol 2002;26:41-44.

78 Mazzaferri EL. Management of a solitary thyroid nodule. N Engl J Med 1993;328:553-559.

79 Kumagai A, Namba H, Akanov Z, et al. Clinical implications of pre-operative rapid BRAF analysis for papillary thyroid cancer. Endocr J 2007;54:399-405.

80 Xing M, Tufano RP, Tufaro AP, et al. Detection of BRAF mutation on fine needle aspiration biopsy specimens: a new diagnostic tool for papillary thyroid cancer. J Clin Endocrinol Metab 2004;89: 2867-2872.

81 Domingues R, Mendonca E, Sobrinho L, et al. Searching for RET/PTC rearrangements and BRAF V599E mutation in thyroid aspirates might contribute to establish a preoperative diagnosis of papillary thyroid carcinoma. Cytopathology 2005;16:27-31.

82 Pizzolanti G, Russo L, Richiusa P, et al. Fine-needle aspiration molecular analysis for the diagnosis of papillary thyroid carcinoma through BRAF V600E mutation and RET/PTC rearrangement. Thyroid 2007;17:1109-1115.

83 Sapio MR, Guerra A, Posca D, et al. Combined analysis of galectin-3 and BRAFV600E improves the accuracy of fine-needle aspiration biopsy with cytological findings suspicious for papillary thyroid carcinoma. Endocr Relat Cancer 2007;14:1089-1097.

84 Sapio MR, Posca D, Raggioli A, et al. Detection of RET/PTC, TRK and BRAF mutations in preoperative diagnosis of thyroid nodules with indeterminate cytological findings. Clin Endocrinol (Oxf) 2007;66:678-683.

85 Jo YS, Huang S, Kim YJ, et al. Diagnostic value of pyrosequencing for the BRAF V600E mutation in ultrasound-guided fine-needle aspiration biopsy samples of thyroid incidentalomas. Clin Endocrinol (Oxf) 2009;70:139-144.

86 Zatelli MC, Trasforini G, Leoni S, et al. BRAF V600E mutation analysis increases diagnostic accuracy for papillary thyroid carcinoma in fine needle aspiration biopsies. Eur J Endocrinol 2009;161:467-473.

87 Cohen Y, Rosenbaum E, Clark DP, et al. Mutational analysis of BRAF in fine needle aspiration biopsies of the thyroid: a potential application for the preoperative assessment of thyroid nodules. Clin Cancer Res 2004;10:2761-2765.

88 Salvatore G, Giannini R, Faviana P, et al. Analysis of BRAF point mutation and RET/PTC rearrangement refines the fine-needle aspiration diagnosis of papillary thyroid carcinoma. J Clin Endocrinol Metab 2004;89:5175-5180.

89 Rowe LR, Bentz BG, Bentz JS. Utility of BRAF V600E mutation detection in cytologically indeterminate thyroid nodules. CytoJournal 2006;3:10.

90 Xing $\mathrm{M}$, Clark $\mathrm{D}$, Guan $\mathrm{H}$, et al. BRAF mutation testing of thyroid fine-needle aspiration biopsy specimens for preoperative risk stratification in papillary thyroid cancer. J Clin Oncol 2009;27: 2977-2982.

91 Marchetti I, Lessi F, Mazzanti CM, et al. A morphomolecular diagnosis of papillary thyroid carcinoma:
BRAF V600E detection as an important tool in preoperative evaluation of fine-needle aspirates. Thyroid 2009;19:837-842.

92 Chung KW, Yang SK, Lee GK, et al. Detection of BRAFV600E mutation on fine needle aspiration specimens of thyroid nodule refines cyto-pathology diagnosis, especially in BRAF600E mutation-prevalent area. Clin Endocrinol (Oxf) 2006;65:660-666.

93 Nikiforov YE, Ohori NP. Papillary carcinoma. In: Nikiforov YE, Biddinger PW, Thompson LDR (eds). Diagnostic Pathology and Molecular Genetics of the Thyroid, Vol. Lippincott Williams \& Wilkins: Baltimore, 2009, pp 160-213.

94 Cheung CC, Carydis B, Ezzat S, et al. Analysis of ret/PTC gene rearrangements refines the fine needle aspiration diagnosis of thyroid cancer. J Clin Endocrinol Metabol 2001;86:2187-2190.

95 Sciacchitano S, Paliotta DS, Nardi F, et al. PCR amplification and analysis of ras oncogenes from thyroid cytologic smears. Diagn Mol Pathol 1994;3: 114-121.

96 Ohori NP, Nikiforova MN, Schoedel KE, et al. Contribution of molecular testing to thyroid fineneedle aspiration cytology of 'follicular lesion of undetermined significance/atypia of undetermined significance'. Cancer Cytopathol 2010;118:17-23.

97 Cooper DS, Doherty GM, Haugen BR, et al. Revised American Thyroid Association management guidelines for patients with thyroid nodules and differentiated thyroid cancer. Thyroid 2009;19: 1167-1214

98 Nikiforova MN, Biddinger PW, Caudill CM, et al. PAX8-PPARgamma rearrangement in thyroid tumors: RT-PCR and immunohistochemical analyses. Am J Surg Pathol 2002;26:1016-1023.

$99 \mathrm{Kim} \mathrm{TY}$, Kim WB, Rhee YS, et al. The BRAF mutation is useful for prediction of clinical recurrence in low-risk patients with conventional papillary thyroid carcinoma. Clin Endocrinol (Oxf) 2006;65:364-368.

100 Kebebew E, Weng J, Bauer J, et al. The prevalence and prognostic value of BRAF mutation in thyroid cancer. Ann Surg 2007;246:466-470; discussion 70-1.

101 Elisei R, Ugolini C, Viola D, et al. BRAF(V600E) mutation and outcome of patients with papillary thyroid carcinoma: a 15-year median follow-up study. J Clin Endocrinol Metab 2008;93:3943-3949.

102 Riesco-Eizaguirre G, Gutierrez-Martinez P, GarciaCabezas MA, et al. The oncogene BRAF V600E is associated with a high risk of recurrence and less differentiated papillary thyroid carcinoma due to the impairment of $\mathrm{Na}+\mathrm{I}$ - targeting to the membrane. Endocr Relat Cancer 2006;13:257-269.

103 Durante C, Puxeddu E, Ferretti E, et al. BRAF mutations in papillary thyroid carcinomas inhibit genes involved in iodine metabolism. J Clin Endocrinol Metab 2007;92:2840-2843.

104 Mazzaferri EL. Management of low-risk differentiated thyroid cancer. Endocr Pract 2007;13:498-512.

105 Rodolico V, Cabibi D, Pizzolanti G, et al. BRAF V600E mutation and p27 kip1 expression in papillary carcinomas of the thyroid $<$ or $=1 \mathrm{~cm}$ and their paired lymph node metastases. Cancer 2007;110:1218-1226.

106 Lee X, Gao M, Ji Y, et al. Analysis of differential BRAF(V600E) mutational status in high aggressive papillary thyroid microcarcinoma. Ann Surg Oncol 2009;16:240-245. 
107 Lupi C, Giannini R, Ugolini C, et al. Association of BRAF V600E mutation with poor clinicopathological outcomes in 500 consecutive cases of papillary thyroid carcinoma. J Clin Endocrinol Metab 2007;92: 4085-4090.

108 Manenti G, Pilotti S, Re FC, et al. Selective activation of ras oncogenes in follicular and undifferentiated thyroid carcinomas. Eur J Cancer 1994;30A:987-993.
109 Garcia-Rostan G, Zhao H, Camp RL, et al. ras mutations are associated with aggressive tumor phenotypes and poor prognosis in thyroid cancer. J Clin Oncol 2003;21:3226-3235.

110 Liu J, Singh B, Tallini G, et al. Follicular variant of papillary thyroid carcinoma: a clinicopathologic study of a problematic entity. Cancer 2006;107: 1255-1264. 